Please quote as: Wieck, E.; Bretschneider, U. \& Leimeister, J. M. (2013): Funding from the crowd: An internet-based crowdfunding platform to support business set-ups from universities. In: International Journal of Cooperative Information Systems (IJCIS), Ausgabe/Number: 3, Vol. 22, Erscheinungsjahr/Year: 2013. Seiten/Pages: 12. 


\title{
FUNDING FROM THE CROWD: AN INTERNET-BASED CROWDFUNDING PLATFORM TO SUPPORT BUSINESS SET-UPS FROM UNIVERSITIES
}

\author{
ENRICO WIECK*, ULRICH BRETSCHNEIDER ${ }^{\dagger}$ \\ and JAN MARCO LEIMEISTER ${ }^{\ddagger}$ \\ Information Systems, Kassel University \\ Pfannkuchstr. 1, 34121 Kassel, Germany \\ *wieck@uni-kassel.de \\ †bretschneider@uni-kassel.de \\ ${ }^{\ddagger}$ leimeister@uni-kassel.de
}

Received 2 November 2012

Accepted 31 August 2013

Published 4 October 2013

\begin{abstract}
This research-in-progress paper presents a research project that aims at developing, piloting and evaluating a crowdfunding platform to support financing for start-ups emerging from university. Currently, universities' own financial resources to support setting up businesses from universities are limited. Universities' business foundation consultancy can often only intermediate between entrepreneurs on the one side and restricted funding programs or few investors on the other side. A crowdfunding platform enables many individuals of the (university) crowd to support promising business ideas with little investments cumulating to a greater sum in total. Thus, it has the potential to extend universities' opportunities to support entrepreneurs. In addition, tasks like idea communication, idea evaluation and investment decisions can be outsourced to the crowd. The idea, research setting, first results and a future outlook of this research project are discussed in this paper.
\end{abstract}

Keywords: Crowdfunding; entrepreneurship; start-ups.

\section{Introduction}

\subsection{Problem statement}

Universities increasingly provide systematic support for entrepreneurs, e.g. with business foundation consultancies, centers for entrepreneurship, business incubators and others. Entrepreneurs willing to start their own business are understood in the scope of this paper as members of a university, for example students or researchers, or citizens affiliated to the university in any form.

There are worldwide discussions about universities and their role in different aspects, for example with respect to research, teaching and economic impact.

*Corresponding author. 
For instance, the triple helix thesis of university-industry-government relations states an enhanced role of universities for innovation in knowledge-based societies. ${ }^{1}$ Biotechnologies and ICT are such exemplary knowledge-based sectors.

However, innovation must also be funded in order to be realized respectively spun-off from universities. In general, universities' departments providing systematic entrepreneur support can often only offer different services. These may include information provision, advice about a business plan or financing calculation as well as access to coaching, networks and business angels. Generalized, current university entrepreneurship services often cover only counseling services. Also, universities may also provide advice regarding funding programs. However, constraints regarding the spending of these funds then might need to be considered, and not all funding request are approved. For example, the German EXIST funding program had an approval rate of $\sim 55 \%$ from 2007 to $2010 .^{2}$ This means that universities might be innovative but they are not capable of implementing the innovation.

\subsection{Solution approach and research goal}

To improve funding for innovative start-ups, universities are not necessarily required to provide funds themselves as this is often difficult due to resource constraints. Instead, they can take a role as a mediator. We think universities can connect investors and entrepreneurs using the crowdfunding principle.

Crowdfunding is about raising "external finance from a large audience (the "crowd"), where each individual provides a [...] small amount, instead of soliciting a small group of sophisticated investors". 3 Web-based crowdfunding platforms in the scope of this paper serve as intermediaries that connect fund seekers and fund providers. This concept can be compared to crowdsourcing, ${ }^{4}$ which refers to organizations that outsource (sourcing) tasks to a large and undefined group of people (crowd). First research indicates that crowdfunding can serve as an alternative way for small entrepreneurial ventures to finance their projects. ${ }^{5}$

We consider crowdfunding as a suitable approach to support universities in mediating between fund providers and fund seekers. Transferring the crowdfunding principle into the domain of universities enables universities to access their huge crowd and networks for funding purposes. Students, alumni, employees, researchers, partners, and many more actors can each provide a certain (small) funding for innovative entrepreneurs. Another effect may come up because the involved individuals stay in contact with their Alma Mater and build new relationships and intensify the existing ones respectively, resulting in networking opportunities for all involved. By opening the investing process for everyone, universities can focus on mediation. Start-ups are enabled to involve potential customers and multiplicators at an early stage. This may lead to improvements of business ideas and higher commitment for support as the crowd might also come up with further ideas. Thus, crowdfunding has the potential to support all involved: university entrepreneurs, 
universities themselves and the university crowd. It offers a new funding opportunity and network and relationship management which mainly require mediation resources.

Therefore, the research goal is to develop a web-based crowdfunding platform to support start-ups emerging from university. To achieve this goal, we plan, pilot and evaluate a crowdfunding platform. This crowdfunding platform shall enable entrepreneurs to present their business ideas so that the interested public can evaluate the idea and decide whether to invest or not. Besides enabling the crowdfunding process itself, multiple further improvements seem possible:

(i) The public's costs to financially support university entrepreneurs will be reduced. Currently, costly travel and communication efforts are required to get in contact with an entrepreneur whose idea appears to be convincing. In the future, contact can be made possible through a web-based platform eliminating time and place restrictions with $24 / 7$ online accessibility. This also allows start-ups to easily reach a potentially very huge investing crowd as some geographical barriers will be reduced in crowdfunding. ${ }^{6}$

(ii) Further capital resources might be addressed. Currently, entrepreneurs mainly have to rely on professional investors' financial resources, funding programs or traditional intermediaries like banks. However, the role of customers changes so that customers nowadays are not only "targets, information sources, coproducers" or "value co-creators", but also investors. ${ }^{7}$ In the future, the crowd's financial resources might serve as a further source of funding for entrepreneurs.

(iii) Knowledge about current business ideas can be better communicated and is better accessible for the interested public. At the moment, only limited information about business ideas is publicly available. In the future, one can easily check for updates on the crowdfunding online platform. ${ }^{5}$

(iv) Entrepreneurs may benefit from the wisdom of the crowd ${ }^{8}$ because a greater number of investors evaluate the business idea before investing. Thereby, investors' engagement by providing funding to a start-up might indicate a possible market success. Furthermore, entrepreneurs might also ensure market success before the production starts when entrepreneurs offer pre-purchasing of products for investors.

\section{Theoretical Background}

\subsection{Concept of crowdfunding in the context of crowdsourcing}

Crowdfunding can be seen as a form of crowdsourcing and thus can be derived from it. ${ }^{9}$ The term crowdsourcing has been coined by Jeff Howe ${ }^{4}$ and relates to outsourcing, that means the transfer of one organization's tasks to another. Instead of outsourcing to another company, crowdsourcing means outsourcing to the crowd, i.e. a large group of individuals, using an open call, commonly through the internet. 
Companies can use crowdsourcing, for example, to involve customers into the company's innovation processes. ${ }^{10}$ This procedure corresponds to the understanding of open innovation. ${ }^{11}$ It furthermore tries to utilize the wisdom of crowds meaning that a group of people can achieve better results than individuals when certain conditions like diversity of opinion, independence and decentralization are given. ${ }^{8}$ Well-known crowdsourcing examples where volunteers collaboratively participate are the online encyclopedia Wikipedia ${ }^{\mathrm{a}}$ and the OpenStreetMap ${ }^{\mathrm{b}}$ project.

The basic idea, i.e. to reach a large group of individuals (the crowd) that collaboratively work together on a common goal, is also found in crowdfunding. The difference is that the crowd in crowdfunding collaborates by each one providing (small) financial resources. Consequently, crowdfunding is seen as "external finance from a large audience (the "crowd"), where each individual provides a very small amount, instead of soliciting a small group of sophisticated investors". 3 Thus, a common goal can be reached with little resources cumulating to the required greater sum in total.

\subsection{Novelty in crowdfunding platforms and market impact}

Pooling money together as a basic principle of crowdfunding is not novel. For example, the pedestal of the Statue of Liberty was partly financed by citizens of New York. In 1885, Joseph Pulitzer announced to print the name of every contributor in the New York newspaper "World". After five months, the donation campaign had raised $\$ 102.000$ with $80 \%$ coming from donors with less than a dollar donation. ${ }^{12}$ Another example, among others, is the yearly Wikipedia donation campaign. ${ }^{13}$

The novelty in crowdfunding platforms is to use web-based platforms as intermediaries. Such a crowdfunding platform enables a user to create a project or undertaking and to ask the crowd to fund this project. Through the use of information systems, transaction $\operatorname{costs}^{14}$ can be minimized. This also allows for funding of only small amounts that can add up to large sums in total.

Web-based crowdfunding platforms increasingly emerge in practice. 452 crowdfunding platforms were counted in April 2012. Overall, in 2011 almost $\$ 1.5$ billion were raised through such crowdfunding platforms and more than 1 million campaigns were successfully funded worldwide. ${ }^{15}$ Most platforms are headquartered in the US followed by Europe. Within the field of crowdfunding platforms, no platform could be identified so far that focuses on university start-ups. There are already platforms for start-up funding and the US-American JOBS Act 2012 raised a lot of attention for such funding platforms. However, these platforms have their own crowd and could therefore not make use of the existing university crowd and all possible advantages as argued before.

\footnotetext{
${ }^{\mathrm{a}}$ www.wikipedia.org

${ }^{\mathrm{b}}$ www.openstreetmap.org
} 


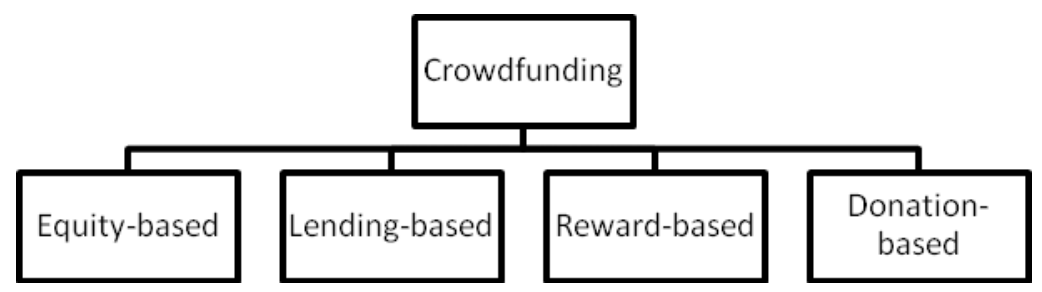

Fig. 1. Crowdfunding types (adapted from Ref. 15).

\subsection{Crowdfunding forms and research}

Crowdfunding can have different forms in practice that are summarized in Fig. 1. These forms highlight the rewards the crowd receives for their funding. In equitybased crowdfunding, start-ups offer parts of their company's equity to investors. Lending-based crowdfunding platforms enable the crowd to lend money and receive interest. Reward-based crowdfunding platforms enable project starters to offer different (nonfinancial) rewards in return for funds, such as acknowledgments, products, services or creative rewards. In donation-based crowdfunding, no explicit rewards are offered to the crowd.

Besides differentiating into different forms, there already is some research about crowdfunding we can base our research project on. An examination of an artistentrepreneurs crowdfunding setting over the internet for financing early stage music projects indicates that crowdfunding influences geographical barriers, beside other factors. ${ }^{6}$ The overall distance of fund seekers and givers can increase, while the first funds are still provided by families, friends and geographical neighbors. Within another paper, data from a reward-based crowdfunding platform with nearly 47.000 projects that raised funding of more than $\$ 198$ million were analyzed to identify determinants of success and failure. ${ }^{16}$ For example, shorter projects (30 days) are more likely to be successfully funded than longer projects (60 days). A video that explains the project also increases chances for successful funding. In Ref. 7, the role of customers in crowdfunding initiatives and how these roles change in crowdfunding compared to other customers' settings were discussed. These findings help to understand the more active role of customers in crowdfunding. However, in total there is only little research about crowdfunding yet, and these papers present first insights in their research field only. Our paper is therefore also designed to add to the body of knowledge of crowdfunding by contributing to crowdfunding platform requirements, operations and evaluation.

\section{Research Approach and Methodology}

Crowdfunding platforms are novel developments that still emerge in practice. As a consequence, an explorative research approach is chosen. We design this research project because of the general situations of universities and seek to contribute to 


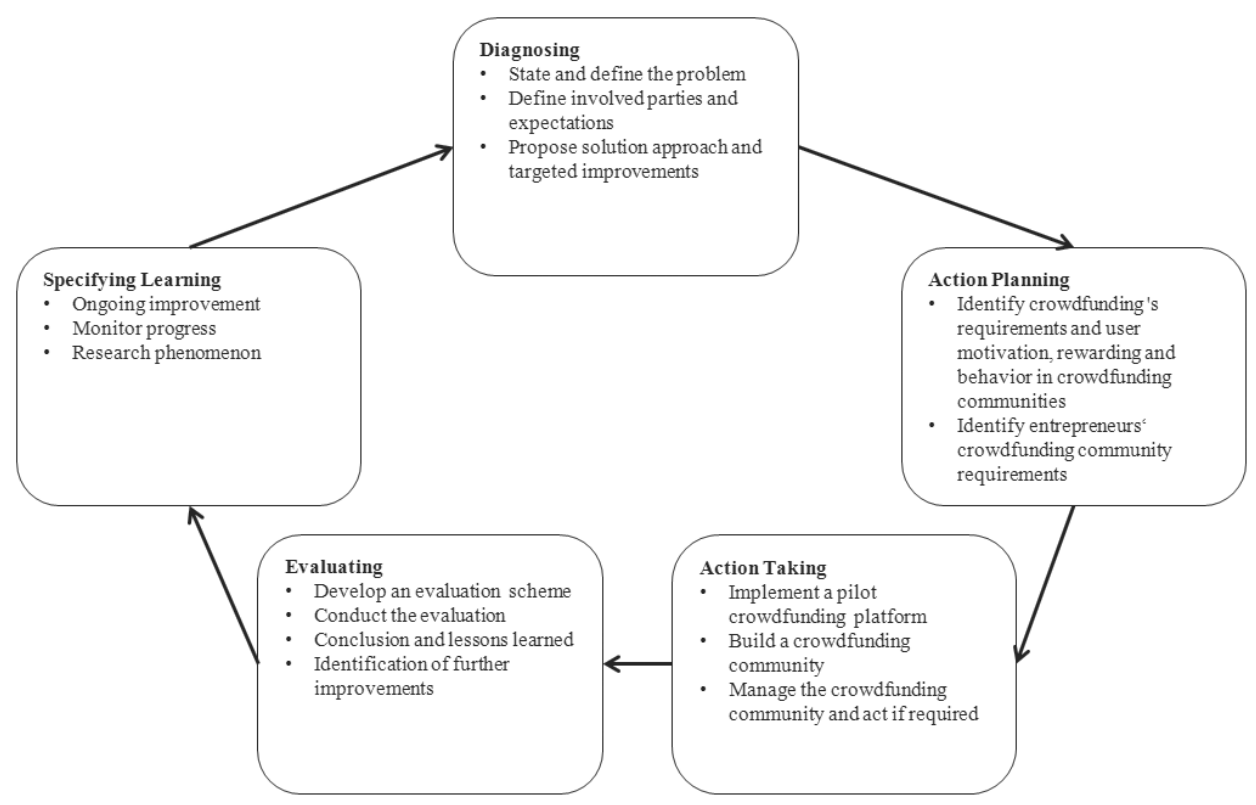

Fig. 2. Action research approach (adapted from Ref. 17).

universities' innovation transfer as initially described. The pilot will be tested in a real university setting together with the universities' incubator.

Taking these arguments into account we therefore design our research as an action research project based on Baskerville's action research cycle. ${ }^{17}$ By doing so, we can continuously improve the artifact as we learn while designing the novel, socio-technical artifact in the form of a crowdfunding platform.

Our research cycle structure referring to Ref. 17 includes the phases diagnosing, action planning, action taking, evaluating and specifying learning, as shown in Fig. 2. In the following, these phases are depicted and explained in more detail. These explanations also include first results gained so far.

\section{Preliminary Design}

\subsection{Diagnosing}

The diagnosing phase covers research on the problem environment to provide a foundation for solution approaches. Within the university setting, different involved parties have specific needs.

Knowledge transfer departments. Incubators or other such departments seek to support innovative start-ups from the university. Often, they coach, advice, enable access to business networks and also access to some funding programs to startups, for example the EXIST funding program. However, there is a need for further funding opportunities as for example EXIST is subject to some restrictions in terms 
of the use of funds and has an approval rate for start-ups finally receiving funding of about $55 \%$ from 2007 to $2010 .^{2}$ This means that only every second application is successful. Also, EXIST does not fit for all potential start-ups so that crowdfunding can serve as a new funding source.

Researcher. Crowdfunding and its mechanisms are not yet well understood. Often, it is rather hard to get access to platforms on the market and some of the required data. Researchers would have a very good source for data right from the field to research on.

University crowd. It is currently rather difficult for the university crowd to get involved into university projects and start-ups, respectively spin-offs, e.g. for students, employees, researcher and in a wider sense the affiliated and local population. A crowdfunding platform can serve this need as it communicates projects, respectively start-ups to everyone with internet access. Users can easily browse the platform and inform themselves, including contact details. Therefore, it is much easier for the university crowd and parts of the population to provide support and get involved.

Start-ups. Finally, start-ups have multiple needs. First, as funding is a key issue, they have a chance to receive funding from the crowd. Second, raising awareness, demand and marketing can be supported through a crowdfunding platform as for example crowdinvestors might attract multipliers and customers as well. Third, crowdinvestors may also provide valuable feedback, ideas and access to relevant networks to support the start-up's success.

The results from the diagnosing phase are summarized in Table 1.

\subsection{Action planning}

The action planning phase specifies the results derived from the diagnosing phase, i.e. we will further concretize a crowdfunding platform for universities regarding to the identified needs.

Table 1. Results of diagnosing phase.

\begin{tabular}{lll}
\hline Involved Party & \multicolumn{1}{c}{ Expectation } & $\begin{array}{c}\text { Solution Approach and } \\
\text { Targeted Improvement }\end{array}$ \\
\hline $\begin{array}{l}\text { Knowledge transfer } \\
\text { departments }\end{array}$ & $\begin{array}{l}\text { Provide further funding } \\
\text { opportunity without restrictions } \\
\text { Researcher }\end{array}$ & $\begin{array}{l}\text { University crowd funds start-ups } \\
\text { as a further source of funding } \\
\text { research }\end{array}$ \\
University crowd & $\begin{array}{l}\text { Get easier involved in university } \\
\text { projects and start-ups with } \\
\text { possibility to provide support }\end{array}$ & $\begin{array}{l}\text { Publish projects/start-ups on } \\
\text { crowdfunding platform }\end{array}$ \\
& $\begin{array}{l}\text { Receive funding, increase } \\
\text { awareness, demand and } \\
\text { marketing, receive support, }\end{array}$ & $\begin{array}{l}\text { Involve university crowd as } \\
\text { investors and multiplicators }\end{array}$ \\
& access to networks & \\
\hline
\end{tabular}


Knowledge transfer departments' daily business is to support start-ups. Therefore, they will operate the platform from a content-perspective. These include responsibility for selecting start-ups as well as advise the start-ups on how to present themselves on the platform. The knowledge transfer department will also be responsible for marketing the platform in order to attract the university crowd for funding.

Researcher will provide advice of their field of expertise. This may cover community building, marketing or design, besides other areas. Also, they will use the platform for their research projects and questions.

University crowd will be informed about the platform before launching the funding of the first projects. This will help as the crowd can then register for the platform, inform about the first start-ups and recommend the platform to friends.

Start-ups will prepare their information for the crowd in advance. For this, they will receive advice from the knowledge transfer department. Internal start-up signals like financial roadmaps are considered important to induce small investors to commit financial resources. ${ }^{18}$ They will also prepare a communications plan to interact with the crowd and provide status updates during the funding time.

Besides these aspects that are specific to certain parties, the following parts of the concept are important as well. To meet the overall requirement of having an easy and understandable way to support start-ups, the platform will start as reward-based crowdfunding. The concept to receive a reward is easier to understand, as it is basically a pre-ordering of a product or service. Thus, start-ups can offer their product or service in advance and benefit from several advantages: (1) The university crowd constitutes the first customers from which the start-up can also receive feedback. (2) The transactions are easily to handle for the startup as offering on the crowdfunding platform is just another channel for their sales process. Thus, there is no additional effort compared to e.g. equity-based investing, where investment regulations and other aspects need to be considered. (3) In case the start-up requires funding and advice for their product development process, they can also offer exclusive rewards to build a customer base in advance. These might be meetings, behind-the-scenes tours or discounted vouchers for the final product.

Further, we will ask local and regional organizations to partner with the crowdfunding platform. This will help promoting the start-ups and their crowdfunding because the number of channels will increase through which the university crowd will be reached.

Finally, we will conduct a market research to identify crowdfunding platform providers. The technical and financial part of the platform will be sourced from the best provider. This is required for two reasons. First, there are several regulations regarding payment handling and transaction security. ${ }^{19}$ A dedicated service provider offers higher standards than a university knowledge transfer departments can likely do. Second, the crowdfunding platform is dedicated to bring start-ups, the university crowd and interested person together so that the focus is not a technical part. Indeed, community building by connecting the different parties together 
and allowing them to fund a start-up is the core of the platform. Therefore, these are the processes to focus on.

Summarized, the basic concept will be about a rewards-based crowdfunding platform to support start-ups. Using local and regional partners, different channels will be used to inform the university crowd. The platform itself will be sourced from a platform provider so that technical and payment processes will be handled by the service partner. Thereby, all parties will focus on the most relevant activities: to support start-ups to receive funding.

\section{Piloting and Evaluation}

\subsection{Action taking}

For the action taking phase, that just recently started, we plan to implement the designed concept. For this, we partner with our university's knowledge transfer department and with a regional business development corporation. We evaluated crowdfunding platform providers and asked them for a bid.

The next steps will be to source the platform and customize it, for example in terms of design. The knowledge transfer department will talk to start-ups and advise them on crowdfunding. Marketing material will be developed as well.

We plan to launch the platform and run it for a two-year period. This ensures a sufficient timeframe to establish and to promote the crowdfunding platform. Also, we plan to do multiple evaluations within this timeframe to evaluate the platform's success and research design. If a research design is evaluated as not successful, we can act and improve the latter one. Therefore, during that time, we as researchers need to monitor the crowdfunding platform and act if required, as this is one of the main characteristics of action research. ${ }^{17}$ The overall goal of action taking is to analyze if and how the developed concept works out and what might be improved.

\subsection{Evaluating}

The evaluating phase is currently planned to be divided into two parts. Part one is about the development of an evaluation scheme, and part two will evaluate the crowdfunding platform in accordance to the evaluation scheme.

As an IT-artifact, the evaluation of the crowdfunding platform should be "summative, assessing value and utility outcomes". ${ }^{20}$ Consequently, the evaluation scheme within this cycle will focus on assessing the crowdfunding platforms efficiency in a real-world setting, namely, its ability to support financing for startups emerging from university. To assess the value and utility of the IT artifact, the research team will have to seek to understand the class of problem defined above. In particular, the lack of funding opportunities was defined as the underlying core problem in this research. We will thus evaluate measures for this core problem and adjacent problems. Possible measures to be evaluated might be usage figures (page impressions, number of users and number of projects), financial figures (raised 
funding per project, in total and per user) and qualitative variables as well (user satisfaction, ease of use, funded projects' impact).

After we have finished the development of the evaluation scheme, we will then use these different measures in order to evaluate and benchmark the platform in part two. Here, several evaluations are required at different times within the project in order to be able to improve the design where necessary. Also, this way allows demonstrating the progress made.

\section{Specifying Learning - Discussion on Expected Outcome and Future Outlook}

The specifying learning phase is an ongoing process, as proposed by Ref. 17. This is especially important in the research project presented here that shall solve the current problem of yet lacking funding support for business start-ups from universities through a crowdfunding platform as a further source of finance.

This research project has practical and theoretical contributions. For practice, this research project supports the knowledge transfer process from research to practice by supporting university start-up financing. It is the first attempt to adapt the crowdfunding concept to a university setting. For theory, the body of knowledge will be extended by evaluating if crowdfunding is also suitable in a university context. So far, crowdfunding platforms cover different areas in practice but it is not yet understood if there are limitations to certain application areas.

Research on crowdfunding platforms also appears meaningful when considering future developments. Crowdfunding is currently in an emerging phase ${ }^{15}$ so that further developments can be expected. In Germany, for example, there are currently many equity-based crowdfunding platforms in the development and market-entry phase. A more visionary view is to categorize start-up funding as an own asset class in a diversified portfolio besides shares of established companies, bonds, commodities and others. Crowdfunding platforms could serve as an enabling technology that helps fund managers to invest a portion of their funds in start-ups. Also, crowdfunding platforms could change the investment behavior of the broad public as it is much easier than ever before to invest some money in a start-up.

Furthermore, we expect to get further insights from our six-month pilot phase, for example on the motivation of the crowd to invest. By doing so, our research will take a step towards explaining the nature of crowd behavior especially in crowdfunding settings.

\section{Conclusion}

This research-in-progress paper presents a concept of a crowdfunding platform to support funding of university start-ups. This platform aims at solving the problem of limited funding support to these start-ups as it is not a university's core business to provide funds. Crowdfunding is introduced as a promising approach. Currently, 
many crowdfunding platforms emerge in practice making different projects possible. Because crowdfunding is a new phenomenon that is scarcely in research yet, we designed this research project as an action research project for continuous learning and appropriate adjustments of the research setting when necessary. First results are presented, especially requirements of the different involved parties and how these needs can be fulfilled. This paper contributes to theory and practice by adopting the crowdfunding principle to university settings and by possibly improving the research to practice knowledge transfer by better funding support for start-ups from universities. The future outlook discusses further developments for crowdfunding and shows that there is still a lot of potential in crowdfunding.

\section{Acknowledgments}

The research presented in this paper was developed within the project, "The Open Innovation Project (IOIT)" funded by the European Union Interreg IVB NWE Programme. This programme provides partial funding for transnational projects in the North West European Co-operation Zone over the period 2007-2013. The priority areas for the programme are: innovation; environmental challenges; connectivity and: promoting strong and prosperous communities. The NWE Zone includes: France, Belgium, Netherlands, Luxembourg, Germany, United Kingdom, Ireland and Switzerland (Funding code: 166F-IOIT)

http://www.nweurope.eu/

http://openinnovationproject.co.uk

\section{References}

1. H. Etzkowitz and L. Leydesdorff, The dynamics of innovation: From national systems and "Mode 2" to a triple helix of university-industry-government relations, Res. Policy 29 (2000) 109-123.

2. C. G. Becker and T. Lübbers, Evaluation der Fördermaßnahmen, EXISTGründerstipendium 'und, EXIST-Forschungstransfer', Endbericht, Gesellschaft für Innovationsforschung und Beratung mbH, Berlin (2011) (in German).

3. P. Belleflamme et al., Crowdfunding: Tapping the right crowd, SSRN eLibrary (2010).

4. J. Howe, The rise of crowdsourcing, Wired Magazine, Vol. 14 (2006).

5. A. Schwienbacher and B. Larralde, Crowdfunding of small entrepreneurial ventures, SSRN eLibrary (2010).

6. A. Agrawal et al., The geography of crowdfunding, SSRN eLibrary (2011).

7. A. Ordanini et al., Crowd-funding: Transforming customers into investors through innovative service platforms, J. Serv. Manag. 22 (2011) 443-470.

8. J. Surowiecki, The Wisdom of Crowds: Why the Many are Smarter Than the Few and how Collective Wisdom Shapes Business, Economies, Societies, and Nations, Vol. 1 (Doubleday Books, New York, 2004).

9. U. Bretschneider and J. M. Leimeister, Schöne neue Crowdsourcing Welt: Billige Arbeitskräfte, Weisheit der Massen? in Virtual Enterprises, Communities and Social Networks; Proc. zum Workshop Gemeinschaft in Neuen Medien (GeNeMe 11) (Dresden, 2011), pp. 1-13 (in German). 
10. J. M. Leimeister et al., Leveraging crowdsourcing: Activation-Supporting components for IT-based ideas competition, J. Manage. Inform. Syst. 26 (2009) 197-224.

11. R. Reichwald and F. Piller, Interaktive Wertschöpfung. Open Innovation, Individualisierung und neue Formen der Arbeitsteilung, 2nd edn. (Gabler, Wiesbaden, 2009).

12. J. Harris, A Statue for America: The First 100 Years of the Statue of Liberty (Four Winds Press, New York, 1986).

13. J. Walsh, Wikimedia fundraiser concludes with record breaking donations, Available at http://blog.wikimedia.org/2012/01/02/wikimedia-fundraiser-concludes-withrecord-breaking-donations/ (accessed on 27 August 2012).

14. O. E. Williamson, Markets and Hierarchies: A Study in the Internal Organizations (Macmillan, USA, 1975).

15. Crowdsourcing LLC, Crowdfunding industry report. Market trends, composition and crowdfunding platforms (Research Report, Abridged Version ed.), Available at http://www.crowdsourcing.org/document/crowdfunding-industry-report-abridgedversion-market-trends-composition-and-crowdfunding-platforms/14277 (2012).

16. E. R. Mollick, The dynamics of crowdfunding: Determinants of success and failure, SSRN eLibrary, 25 July, 2012.

17. R. L. Baskerville, Investigating information systems with action research, Commun. Assoc. Inform. Syst. 2 (1999) 1-32.

18. G. K. C. Ahlers et al., Signaling in equity crowdfunding, SSRN eLibrary (2012).

19. BaFin, Crowdfunding im Licht des Aufsichtsrechts. Was Plattformbetreiber und kapitalsuchende Anbieter von Beteiligungsmöglichkeiten beachten müssen, BaFin J. Mitteilungen der Bundesanstalt für Finanzdienstleistungsaufsicht 9 (2012) 11-15.

20. M. Sein et al., Action design research, Manag. Inform. Syst. Q 35(1) (2011) 37-56. 